\title{
A lot to learn
}

\section{The changing face of nanoscience education around the world.}

As a quick glance through an issue of Nature Nanotechnology will confirm, nanotechnology is a diverse research field, and the educational background of its participants is equally varied. Researchers can emerge from undergraduate degrees in the natural sciences (be it physics, chemistry or biology), in engineering (be it chemical, electrical or mechanical), and other topics in between and beyond. This diversity is, of course, a key characteristic of the field and has been essential to its success. And like any successful field, advances in research would be expected to influence the curricula being taught at universities. However, if nanotechnology is a field defined by a length scale and not traditional subject areas, has it had a more profound effect on education? And what sort of education do future nanotechnologists need in order to thrive? In this issue of Nature Nanotechnology, we consider such questions in a Focus on education.

\section{What sort of education do future nanotechnologists need in order to thrive?}

To begin, we asked a range of current, or recently graduated, masters and $\mathrm{PhD}$ students to discuss their own nanoscience education and the ways in which their experience could have perhaps been improved (page 794). The students have attended institutions in a number of different countries - the US, China, the UK, France, Switzerland, Armenia, India and Australia - and have undergraduate degrees in traditional subjects such as physics and chemistry, as well as newer degrees in nanoscience itself. Their reasons for choosing the field are various and their education experiences distinct. However, the importance of an interdisciplinary approach is a recurring theme, and the suggestion that nanotechnology should feature more prominently in the education of school children is highlighted more than once.

One further point that is noted by the students is that taught degree courses do not necessarily provide an appreciation for the trials of actually doing research. Indeed, undergraduate students often a play

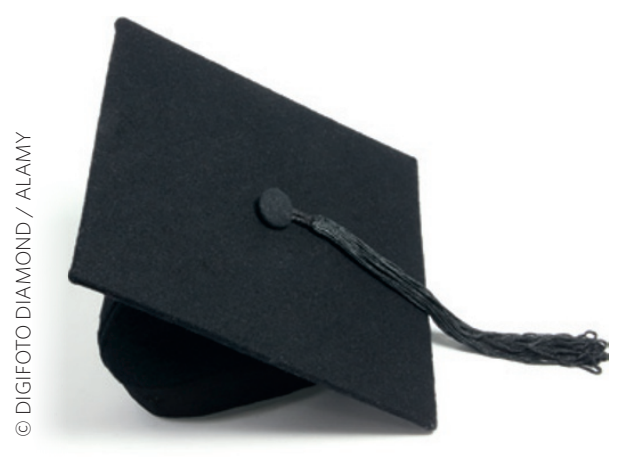

a very limited role in an active research group. In the first of four Commentary articles in this issue, Philip Lukeman explains his approach to mentoring undergraduates in the lab and provides advice for improving the experience for both the undergraduates and the mentors (page 784). In particular, he highlights a series of points that should be made clear to all undergraduate researchers, and provides advice on recruiting and training students. As with most aspects of education, techniques for mentoring students need to be constantly reassessed and refined, and the author is keen to receive feedback and suggestions regarding best practices for mentoring undergraduates.

In the second Commentary, Krishna Madhavan, Michael Zentner and Gerhard Klimeck examine the impact online resources can have on both teaching and research in nanotechnology (page 786). They discuss, in particular, the growth and use of nanoHUB, a cyberenvironment focused on modelling and simulations. nanoHUB was launched in 1998 and now has over 280,000 annual users, which potentially makes it the largest nanotechnology user facility in the world. Key to the endeavor is the view that research and teaching are inextricably linked, and such online environments can help connect teachers and students with the research community.

nanoHUB, which is funded by the United States National Science Foundation, has a global list of users, but changes to the curricula of higher-education institutions around the world are still strongly influenced by national circumstances and concerns. In a Commentary on page 789 , Tebello Nyokong and Janice Limson look at nanoscience education in South Africa. As the authors explain, a nanotechnology research infrastructure emerged relatively late in the country. However, driven by the country's National Nanotechnology Strategy, research activities in the field have grown in the past decade and have begun to influence the curricula of universities in the country. In 2012, for example, a team of four universities the University of Johannesburg, the University of the Western Cape, University of the Free State and Nelson Mandela Metropolitan University - launched the nation's first master's degree in nanoscience. The approach and focus to developments in education in South Africa are, however, unique to the country and reflect its relatively limited resources, its national priorities (such as poverty reduction), and its strengths (such as rich mineral resources).

In our final Commentary, Roberto Cingolani considers the past and future of nanoscience education (page 792). He suggests that although nanotechnology has provided a common ground for the traditional scientific disciplines, university education will in the future splinter into focused nanotech domains in a similar way to how research in engineering fragmented in the past century. He also notes that it is likely that a standard undergraduate degree will be too short a time to teach everything required of a future nanoscientist and it will require "a long-term educational strategy involving the entire pipeline of the undergraduate degree and PhD".

\section{The importance of an interdisciplinary approach is a recurring theme.}

Whether the future Richard Smalleys (who studied chemistry as an undergraduate) or Heinrich Rohrers (who studied physics as an undergraduate) will major in 'nanoscience' or 'nanotechnology' remains to be seen. However, the importance of an interdisciplinary education and approach in the field seem clear. For Nature Nanotechnology, this Focus issue is just the start of a regular spotlight on education in the journal. 